NBER WORKING PAPER SERIES

\author{
TERM, INFLATION, AND FOREIGN \\ EXCHANGE RISK PREMLA: \\ A UNIFIED TREATMENT
}

Lars E. O. Svensson

Working Paper No. 4544

\author{
NATIONAL BUREAU OF ECONOMIC RESEARCH \\ 1050 Massachusetts Avenue \\ Cambridge, MA 02138 \\ November, 1993
}

I thank Magnus Dalhquist, Bemard Dumas, Nils Gottfries, John Hassler, Lars Ivarsson, Harald Lang, Hans Lindberg, Ragnar Lindgren, Mats Persson, Peter Sellin, Philippe Weil, and participants in seminars at Board of Governors of the Federal Reserve System, HEC, IIES, Göteborg University and Umed University for discussions and comments; and Molly Akerlund for secretarial and editorial assistance. Remaining errors are my own. This paper is part of NBER's research program in International Finance and Macroeconomics. Any opinions expressed are those of the author and not those of the National Bureau of Economic Research. 
NBER Working Paper \#4544

November 1993

\title{
TERM, INFLATION, AND FOREIGN \\ EXCHANGE RISK PREMLA: \\ A UNIFIED TREATMENT
}

\begin{abstract}
The paper reviews the theoretical foundations of the use of forward interest rates to infer expected future rates of interest, inflation, currency depreciation and inflation differentials. Forward rates are related to these expected future variables via combinations of term, inflation and foreign exchange risk premia. A unified derivation, discussion and comparison of these premia is provided under both general and specific assumptions, as well as some comments on empirical estimation.
\end{abstract}

Lars E. O. Svensson

Institute for International Economic Studies

Stockholm University

S-106 91 Stockholm

SWEDEN

and NBER 


\section{Introduction}

The recent collapse of European exchange rate regimes with fixed exchange rates to regimes with floating rates forces the central banks of the countries concerned to reconsider the targets, indicators and instruments that constitute the monetary policy regimes. Monetary policy with a floating exchange rate is more complicated than with a fixed exchange rate. Indicators of inflation pressure, inflation expectations, and the monetary policy stance become more important than when the policy just consists of defending the intermediate target of a fixed exchange rate.

The yield curve is frequently used as an indicator of expectations of future interest and inflation rates. However, the forward rate curve, consisting of the forward interest rates implicit in the yield curve, appears to be a more appropriate indicator than the yield curve. This is because the forward rate curve indicates the expected future time-path of the variables of concern, whereas the standard yield curve only indicates expected future averages of these variables.

The paper examines the theoretical foundations of the forward rate curve as an indicator. It relates the forward rate curve to the expected time path of, respectively, future interest rates, future inflation rates, future currency depreciation rates, and future inflation rate differences across countries. This requires the derivation and examination of the relevant risk premia: the term, inflation, and foreign exchange risk premia. In the literature three different term premia are discussed (and sometimes confused): forward, holding period, and rollover term premia. For the present purpose the forward term premium is the relevant one. Under specific but not unreasonable assumptions convenient and intuitive expressions for the relevant premia are derived and discussed.

The paper provides a unified treatment of term, inflation and foreign exchange risk premia by combining and borrowing from a large literature. The literature on the term structure of interest rates and term premia is surveyed by Shiller (1990). Breeden (1986) provides a synthesis of the literature on inflation risk premia and the Fisher equation, and 
provides references to the earlier literature. Adler and Dumas (1983) and Hodrick (1987) survey the literature on the foreign exchange risk premium.

The paper states general expressions for the different premia with a general framework borrowed from Shiller (1990) and from Breeden's (1986) treatment of the inflation risk premium. It exploits the conditional lognormality assumption, as in Breeden (1986), to get specific easily interpreted expressions. The expressions are further clarified with specific assumptions about the underlying utility function, one specification being a time-separable utility function with constant relative risk aversion as in Breeden (1986).

The paper's contribution, if any, is in the unified and parallel derivation and discussion of the different premia; in the clarification of what combinations of premia are involved in extracting expected future interest, inflation, currency depreciation, and inflation differential rates from forward rates; and in the comparisons of the different premia in these combinations under increasingly specific assumptions; all as a step in assessing the possibility to use forward rates in order to extract expectations of future interest, inflation and currency depreciation rates.

To start with, I will give some preliminary definitions and define five issues to be dealt with.

Let $i(l, T)$ denote the (nominal) spot (interest) rate, the yield to maturity on a (nominal) pure discount bond purchased at time $/$ the trade date, which matures at time $T>t$, the maturity date. The limit of the spot rate $i(l, t+\tau)$ when the time to maturity $\tau$ $=T-t$ approaches zero is denoted by $i(t)$ and called the instantaneous spot rate. The yield curve at time $t$ is the spot rates $i(t, T)$ plotted against different maturity dates $T>t$, (or, alternatively, the interest rates $i(t, t+\tau)$ plotted against different times to maturity $\tau) .1$

Let $f\left(l, l^{\prime}, T\right)$ denote the (nominal) forward (interest) rate, that is, the nominal interest rate determined at time $l$, the trade date, for the promised lending of cash from time $l^{\prime}$,

1. Bonds with time to maturity above one year are usually not discount bonds but coupon bonds. Estimating implicit spot rates, that is, yeilds to maturity on discount bonds from yields to maturity on coupon bonds is a separate problem not discussed here. 
the settlement date, to time $T$, the maturity date, $\left(t<t^{\prime}<T\right)$. A forward rate curve at time $t$ is a plot of forward rates $f\left(t, t^{\prime}, t^{\prime}+\tau\right)$ against future settlement dates $t^{\prime}>t$, for fixed time to maturity $\tau>0$. Hence, there are several forward rate curves at time $t$ : one for each maturity $\tau$. The limit of the forward rate $f\left(t, l^{\prime}, t^{\prime}+\tau\right)$ when the time to maturity $\tau$ approaches zero is denoted by $f\left(t, t^{\prime}\right)$ and called the instantaneous forward rate. The instantaneous forward rate curve at time $t$ is the plot of the forward instantaneous rates $f\left(t, t^{\prime}\right)$ against future settlement dates $t^{\prime}>\ell$ (or, alternatively, a plot of $f(t, t+\tau)$ against $\tau$ $>0$ ). The forward rate curves are implicit in the yield curve, and the implicit forward rates $f\left(t, t^{\prime}, T\right)$ and $f\left(t, t^{\prime}\right)$ can be derived from the spot rates $i\left(t, t^{\prime}\right)$.

The thick dashed curve in Figure $l$ shows an example of a yield curve at time $t$, that is, the spot rates $i\left(t, t^{\prime}\right)$ at the trade date $t$ plotted against times to maturity $t^{\prime}-t \geq 0$. The yield curve has been drawn with a U-shape (which is what the Swedish yield curve looked like in spring 1993). The thick solid curve shows the corresponding instantaneous forward rate curve at time $t$, that is, the instantaneous forward rates $f\left(t, t^{\prime}\right)$ at the trade date $t$ plotted against times to settlement $t^{\prime}-t \geq 0$.

The yield and forward rate curves are actually related as average and marginal cost curves: They coincide for zero maturity (when $t^{\prime}=t$ ), the forward rate curve lies below the yield curve when the latter is decreasing, cuts the yield curve where the latter has a minimum, and lies above the yield curve when the latter is increasing.

The discussion in the paper will be organized around five issues. Under the hypothetical case of subjectively certain expectations, which includes the case of perfect foresight but also the case with point expectations when there is actual uncertainty, the forward rate equals the expected future spot rate, $f\left(t, t^{\prime}\right)=\mathrm{E}_{t} i\left(t^{\prime}\right)$ ( $\mathrm{E}_{t}$ denotes expectations with respect to information available at time $t$ ). A first issue is then to what extent forward rates indicate expected future interest rates also with subjectively uncertain expectations. When the overnight spot interest rate is the monetary policy instrument, which is the case in many countries, it is especially important whether the 
overnight forward rates indicate expected future overnight spot rates. The overnight forward rate curve (which will for practical purposes coincide with the instantaneous forward rate curve) then indicates the expected future time path of the overnight spot rates, and hence market expectations of future monetary policy as this is materialized in overnight spot rates. The issue boils down to examining the difference between the forward rate $f\left(t, t^{\prime}, t^{\prime}+\tau\right)$ and the expected future spot rate, $\mathrm{E}_{t} i\left(t^{\prime}, t^{\prime}+\tau\right)$, especially for short maturities $\tau$. The difference equals the nominal (forward) term premium, to be further examined below.

Let $r\left(t, t^{\prime}\right)$ denote the real spot rate at time $t$ on a real discount bond that matures at time $t^{\prime}$. Let $g\left(t, t^{\prime}, T\right)$ and $g\left(t, t^{\prime}\right)$ denote the corresponding finite-maturity and instantaneous real forward rates. The thin curves in Figure 1 show an example of a real yield curve and a real forward rate curve. They are also related as average and marginal cost curves. The forward real rate curve has been drawn decreasing at first and then leveling out, resulting in decreasing real yield curve.

Let $\pi\left(t, t^{\prime}\right)$ denote the average inflation rate from time $t$ to time $t^{\prime}>t$, defined as $\pi\left(t, t^{\prime}\right) \equiv \ln \left[P\left(t^{\prime}\right) / P(t)\right] /\left(t^{\prime}-t\right)$ (where $\ln$ denotes the natural logarithm and $P(t)$ denotes the price level at time $t)$. Let the instantaneous inflation rate at time $t$, the limit of $\pi\left(t, t^{\prime}\right)$ when $t$ approaches $t$, be denoted by $\pi(t)$ (when the limit exists). Under subjectively certain expectations, the (nominal) forward rate equals the sum of the real forward rate and the expected future inflation rate, $f\left(t, l^{\prime}\right)=g\left(t, l^{\prime}\right)+\mathrm{E}_{t} \pi\left(t^{\prime}\right)$. The difference between the nominal and real forward rate curves in Figure 1 then shows the expected future time path of the inflation rate. ${ }^{2}$

A second issue is then to what extent forward rates indicate expected future inflation rates also without subjectively certain expectations. If so, the forward rate curve

2 If the limit $\pi(t)$ does not exist, for instance when $P(t)$ is a diffusion process, we can replace $\mathrm{E}_{t^{n}}\left(t^{\prime}\right)$ by $\mathrm{E}_{\mu_{p}}\left(l^{\prime}\right)$, where $\mu_{p}\left(l^{\prime}\right)$ is the drift of the log price level, the expected instantaneous inflation rate, defined by ${ }_{p}(t) \equiv \lim _{T \rightarrow t^{\prime}} \mathrm{E}_{t}, \pi\left(t^{\prime}, T\right)$. 
$f\left(t, t^{\prime}, t^{\prime}+1\right)$ for one year maturity, say, can be used as an indicator of the expected time path of future yearly inflation rates. In contrast, the standard yield curve at time $t$ of spot rates $i\left(t, t^{\prime}\right)$ would only indicate the average inflation rate from time $t$ to time $t^{\prime}$.

This second issue involves several comparisons. One is a direct comparison of the forward rate $f\left(t, t^{\prime}, t^{\prime}+\tau\right)$ with the expected future inflation rate, $\mathbf{E}_{t} \pi\left(t^{\prime}, t^{\prime}+\tau\right)$. The difference will be the sum of three terms: the expected future real interest rate, the term premium, and the inflation risk premium. However, if a real yield curve is available, with corresponding real forward rates, a second comparison is between the difference between the nominal and real forward rates, $f\left(t, t^{\prime}, t^{\prime}+\tau\right)-g\left(t, t^{\prime}, t^{\prime}+\tau\right)$, and the expected future inflation rate, $\mathrm{E}_{t} \pi\left(t^{\prime}, t^{\prime}+\tau\right)$. This difference will equal the sum of two terms: the difference between the nominal and real term premia, and the inflation risk premium.

A third issue is to what extent the difference between domestic and foreign forward rates indicates the difference between expected future domestic and foreign currency interest rates (which according to the above will be the case under subjectively certain expectations). Especially, to what extent does the difference between the domestic and foreign forward rate curves indicate the expected time-path of future differences between domestic and foreign overnight interest rates, and hence expected differences between domestic and foreign monetary policy? This involves comparing $f\left(t, t^{\prime}, t^{\prime}+\tau\right)-$ $f^{*}\left(t, t^{\prime}, t^{\prime}+\tau\right)$ with $\mathrm{E}_{\boldsymbol{l}}\left[i^{\prime}\left(l^{\prime}, t^{\prime}+\tau\right)-\imath^{*}\left(l^{\prime}, l^{\prime}+\tau\right)\right]$, especially for short maturities $\tau$ (foreign currency nominal forward rates and interest rates are denoted by a star). The difference will equal the difference between the domestic and foreign term premia.

Let $\delta\left(t, t^{\prime}\right)$ denote the average domestic currency rate of depreciation from time $t$ to time $t^{\prime}>t$, defined as $\delta\left(t, l^{\prime}\right) \equiv \ln \left[S\left(t^{\prime}\right) / S(t)\right] /\left(l^{\prime}-t\right)$ (where $S(t)$ denotes the exchange rate, the price of foreign exchange expressed in domestic currency units per foreign currency unit). Let the instantaneous depreciation rate at time $t$, the limit of $\delta\left(t, t^{\prime}\right)$ when $l^{\prime}$ approaches $t$, be denoted by $\delta(t)$ (when the limit exists). Under subjectively certain expectations, the difference between the domestic and foreign nominal forward rates will 
equal the expected future depreciation rate, $\int\left(t, l^{\prime}\right)-f^{*}\left(t, t^{\prime}\right)=\mathrm{E}_{t} \delta\left(t^{\prime}\right) .^{3}$

Figure 2 shows examples of domestic and foreign currency yield curves and forward rate curves. The domestic and foreign currency curves are drawn similar to the empirical krona and deutsche mark curves in spring 1993. Under subjectively certain expectations the difference between the domestic and foreign currency forward rate curves hence show the expected time path of the future domestic currency depreciation rate.

A fourth issue is then to what extent the difference between domestic and foreign forward rate curves indicates the expected time path of future domestic currency depreciation also without subjectively certain expectations. The discrepancy will equal the sum of the foreign exchange risk premium and the difference between the domestic and foreign term premium.

A fifh issue, finally, is whether differences between domestic and foreign forward rates indicate the expected time path of future differences between domestic and foreign inflation rates, $\mathrm{E}_{l}\left[\pi\left(l^{\prime}, l^{\prime}+\tau\right)-\pi^{*}\left(l^{\prime}, l^{\prime}+\tau\right)\right]$, without subjectively certain expectations (as it would under subjectively certain expectations). The discrepancy will equal the sum of three terms: the difference between the expected future domestic and foreign real interest rates, the difference between the domestic and foreign inflation risk premia, and the difference between the domestic and foreign term premia.

The outline of the paper is as follows. Section II presents standard definitions of spot and forward interest rates. Section III derives nominal and real term premia and relates forward rates and expected future interest rates, the first issue. Section IV derives inflation risk premia, and section $\mathrm{V}$ relates forward rates and expected future inflation rates, the second issue. Section VI derives foreign exchange risk premia and relates forward rates to expected future currency depreciation rates and to expected future

3 If the limit $\delta(l)$ does not exist, for instance when $S(t)$ is a diffusion process, we can replace $\mathrm{E}_{t} \delta\left(l^{\prime}\right)$ by $\left.\mathrm{E}_{t_{s}} l^{\prime}\right)$, where $\mu_{s}\left(l^{\prime}\right)$ is the drift of the log exchange rate, the expected instantaneous currency depreciation rate, defined by $\mu_{s}\left(l^{\prime}\right) \equiv \lim _{T \rightarrow l^{\prime}} \mathrm{E}_{t^{\prime}} \delta\left(l^{\prime}, T\right)$. 
inflation differential rates, the third through the fifth issues. Section VII briefly comments on how to empirically estimate the premia. Section VIII concludes. An appendix includes some technical details.

\section{Spot and Forward Interest Rates}

This section states standard definitions and relations between spot and forward interest rates (cf. Shiller (1990)). Let $Q(t, T)$ denote the nominal value at time $t$ of a nominal pure discount bond that matures at time $T$ and then pays one unit of money. Let $\{(t, T)$ denote the real value (in terms of a composite consumption good) at time $t$ of a real pure discount bond that matures at time $T$ and then pays one unit of the composite consumption good. Then the nominal and real yields to maturity, that is, the nominal and real spot (interest) rates at time $t$ of maturity $T-t>0, i(t, T)$ and $r(i, T)$, are defined by the relations 4

$$
Q(t, T) \equiv \exp [-i(t, T)(T-\ell)] \text { and } q(t, T) \equiv \exp [-r(t, T)(T-t)] .
$$

Equivalently, the nominal and real spot rates are given by

$$
i(t, T) \equiv-\ln [Q(t, T)] /(T-l) \text { and } r(t, T) \equiv-\ln [x(t, T)] /(T-t)
$$

The instantaneous(-maturity) nominal and real spot rates at time $t, i(t)$ and $r(t)$ are defined by

4 The interest rate $i\left(t, t^{\prime}\right)$ is continuously compounded (at an annual rate, that is, time is measured in years). Calculations and comparisons are easiest if all rates are expressed as continuously compounded. Interest rates can also be compounded with any finite interval (see Shiller $(1990)): i\left(t, t^{\prime}, h\right) \equiv \exp \left[i\left(t, t^{\prime}\right) h\right]-1$ is the interest rate compounded with an interval of $h$ years at an annual rate. For $h=1$ year it is annually compounded at an annual rate, the interest rate usually used for bonds with maturity above one year ("effective" annualized rates). Another way to express interest rate is $-i\left(t, l^{\prime}\right) \equiv$ $\exp \left[i\left(t, t^{\prime}\right)\left(t^{\prime}-t\right)\right]-1$, the period interest rate (for period $\left.\left(t^{\prime}-t\right)\right)$. The rate $i\left(t, t^{\prime}, h\right) \equiv$ $i\left(t, t^{\prime}\right) h /\left(t^{\prime}-t\right)$ is the simple $h$-period interest rate. For $h$ equal to one 1 year, it is the simple annualized rate usually used for treasury bills and short-term rates below one year maturity.

For very short maturities (overnight, for instance), continuously compounded and simple annualized rates coincide. Annually compounded annualized interest rates are higher than continuously compounded interest rates. Simple annualized rates are lower than annually compounded annualized interest rates for maturities less than one year. 


$$
\begin{gathered}
i(t) \equiv \lim _{T \rightarrow t} i(t, T) \equiv-\partial \ln [Q(t, T)] / \partial T \text { and } \\
r(t) \equiv \lim _{T \rightarrow t} r(t, T) \equiv-\partial \ln [\chi(t, T)] / \partial T,
\end{gathered}
$$

(when the limit and partial derivatives exist).

The nominal and real (implicit) forward rates at time $t$ with settlement at time $t^{\prime \prime}>t$ and maturity at time $T>t^{\prime}, f\left(t, t^{\prime}, T\right)$ and $g\left(t, t^{\prime}, T\right)$, are defined by

$$
\begin{gathered}
f\left(t, t^{\prime}, T\right) \equiv\left[i(t, T)(T-t)-i\left(t, t^{\prime}\right)\left(t^{\prime}-t\right)\right] /\left(T-t^{\prime}\right) \text { and } \\
g\left(t, t^{\prime}, T\right) \equiv\left[r(t, T)(T-t)-r\left(t, t^{\prime}\right)\left(t^{\prime}-t\right)\right] /\left(T-t^{\prime}\right) .
\end{gathered}
$$

The instantaneous(-maturity) nominal and real forward rates, $f\left(t, t^{\prime}\right)$ and $g\left(t, t^{\prime}\right)$, are defined by

$$
f\left(t, l^{\prime}\right) \equiv \lim _{T \rightarrow t^{\prime}} f\left(t, t^{\prime}, T\right) \text { and } \not\left(t, t^{\prime}\right) \equiv \lim _{T \rightarrow t^{\prime}},\left(t, t^{\prime}, T\right) \text {. }
$$

The finite-maturity forward rates will be averages of instantaneous forward rates,

$$
\begin{gathered}
f\left(t, l^{\prime}, T\right) \equiv \int_{\tau=\ell^{\prime}}^{T} f(t, \tau) d \tau /\left(T-l^{\prime}\right) \text { and } \\
g\left(t, t^{\prime}, T\right) \equiv \int_{\tau=l^{\prime}}^{T} g(t, \tau) d \tau /\left(T-l^{\prime}\right) .
\end{gathered}
$$

Furthermore, the instantaneous forward rates and the finite-maturity spot rates are related as marginal and average cost,

$$
\begin{gathered}
f\left(t, t^{\prime}\right) \equiv i\left(t, t^{\prime}\right)+\left(t^{\prime}-t\right) \partial i\left(t, t^{\prime}\right) / \partial t^{\prime} \text { and } \\
g\left(t, t^{\prime}\right) \equiv r\left(t, t^{\prime}\right)+\left(t^{\prime}-t\right) \partial r\left(t, t^{\prime}\right) / \partial t^{\prime} \text {, or } \\
i\left(t, t^{\prime}\right) \equiv \int_{\tau=t}^{l^{\prime}} f(t, \tau) d \tau /\left(t^{\prime}-t\right) \text { and } r\left(t, t^{\prime}\right) \equiv \int_{\tau=t}^{t^{\prime}} g(t, \tau) d \tau /\left(t^{\prime}-t\right) .
\end{gathered}
$$

It follows from (2.7) and (2.1a) that the forward rates also fulfill

$$
f\left(t, t^{\prime}\right) \equiv-\left[\partial Q\left(t, t^{\prime}\right) / \partial t^{\prime}\right] / Q\left(t, t^{\prime}\right) \text { and } \not\left(t, t^{\prime}\right) \equiv-\left[\partial \phi\left(t, t^{\prime}\right) / \partial t^{\prime}\right] / \not\left(t, t^{\prime}\right) \text {. }
$$

Below I shall also use the property that the forward rates at time ! with settlement at time $t$ equal the spot rates at time $t$,

$$
f(t, t, T) \equiv i(t, T) \text { and } r(t, t, T) \equiv r(t, T) .
$$

Let me also define the nominal holding period return $h\left(t, t^{\prime}, T\right)$, the rate of return on holding a bond maturing at time $T$ from time $l$ to $t$, as

$$
\exp \left[h\left(t, t^{\prime}, T\right)\left(t^{\prime}-t\right)\right] \equiv Q\left(t^{\prime}, T\right) / Q(t, T) \text {, or }
$$

(2.9b) $h\left(t, t^{\prime}, T\right) \equiv \ln \left[Q\left(t^{\prime}, T\right) / Q(t, T)\right] /\left(t^{\prime}-l\right) \equiv\left[i(t, T)(T-l)-i\left(l^{\prime}, T\right)\left(T-l^{\prime}\right)\right] /\left(t^{\prime}-t\right)$, 
where I have used (2.1a).

\section{Term Premia}

The first issue is to what extent nominal forward rates indicate expected future nominal interest rates. This boils down to examining the determinants of the nominal (forward) term premium, defined as the excess of the forward rate over the expected future spot rate,

$$
\varphi\left(t, t^{\prime}, T\right) \equiv f\left(t, t^{\prime}, T\right)-\mathrm{E}_{i} i\left(t^{\prime}, T\right)
$$

The term premium can be interpreted as the expected excess return on a forward contract that is financed on the spot market. More precisely, $f\left(t, l^{\prime}, T\right)-i\left(l^{\prime}, T\right)$ is the excess return on a forward contract at time $t$ to lend cash from the future settlement date $l$ to time $T$, when the forward contract is financed by borrowing on the spot market at time $t^{\prime}$.

The forward term premium is related to a second term premium, the holding period term premium,

$$
\varphi_{h}\left(l, l^{\prime}, T\right) \equiv E_{l} h\left(l, l^{\prime}, T\right)-i\left(t, t^{\prime}\right)
$$

defined as the expected excess of the holding return $h\left(t, t^{\prime}, T\right)$ over the spot rate $i\left(t, t^{\prime}\right)$. It follows from (2.3a) and (2.9b) that the excess holding return is proportional to the excess return on the forward contract,

$$
\left[h\left(t, l^{\prime}, T\right)-i\left(t, t^{\prime}\right)\right]\left(l^{\prime}-t\right) \equiv\left[f\left(l, l^{\prime}, T\right)-i\left(t^{\prime}, T\right)\right]\left(T-t^{\prime}\right) .
$$

Hence the holding period term premium is proportional to the forward term premium,

$$
\varphi_{h}\left(t, t^{\prime}, T\right) \equiv \varphi\left(t, t^{\prime}, T\right)\left(T-t^{\prime}\right) /\left(t^{\prime}-t\right)
$$

The forward term premium is also related to a third term premium, the rollover term premium $\nu_{r}\left(l, t^{\prime}, \tau\right)$, defined as the excess of the return on holding a bond from time $t$ to its maturity at time $t$ ' over the expected return on rolling over a short bond of maturity $i$ a total of $n$ times, where $\tau=\left(t^{\prime}-t\right) / n$ and $n$ is an integer. That is,

$$
\varphi_{r}\left(l, l^{\prime}, \tau\right) \equiv i\left(l, l^{\prime}\right)-(1 / n) \Sigma_{j=1}^{\infty} \mathrm{E}_{l} h(l+(j-1) \tau, l+j \tau, l+j \tau)
$$




$$
\equiv i\left(t, t^{\prime}\right)-(1 / n) \Sigma_{j=1}^{\infty} \mathrm{E}_{t} i(t+(j-1) \tau, t+j \tau, t+j \tau) .
$$

Since $i\left(t, t^{\prime}\right) \equiv(1 / n) \Sigma_{j=1}^{\infty} f(t+(j-1) \tau, t+j \tau, t+j \tau)$, it follows from (3.1) that

$$
\varphi_{r}\left(t, l^{\prime}, \tau\right) \equiv(1 / n) \Sigma_{j=1}^{\infty} \gamma(t, t+(j-1) \tau, t+j \tau)
$$

The rollover term premium equals the average future forward term premia of maturity $\tau$.

Here the forward term premium is in focus, rather than the holding period and rollover term premia. From now on the forward term premium is just called the term premium. In order to derive an expression for the nominal term premium, I assume that the nominal price of a pure nominal discount bond, $Q(\ell, T)$, in equilibrium is determined as in a standard asset pricing model by

$$
Q(t, T)=\mathrm{E}_{t}[\mathcal{K}(t, T) P(t) / P(T)] .
$$

Here $\mathscr{K}(t, T)$ denotes a representative investor's real marginal rate of substitution between time $t$ and time $T>t$, that is, the marginal rate of substitution of real wealth at time $T$ for real wealth at time $t ; P(l)$ is the nominal price level at time $t$. Then $\mathscr{K}(t, T) P(t) / P(T)$ is the nominal marginal rate of substitution between time $t$ and time $T$, that is, the marginal rate of substitution of nominal wealth at time $T$ for nominal wealth at time $t$. Consequently (A1a) states that the nominal price of the nominal discount bond equals the expected marginal rate of substitution for nominal wealth. ${ }^{5}$

I shall also assume that

(A2) $\mathcal{K}(t, T)$ and $P(t) / P(T)$ are jointly conditionally lognormal for all $t$ and $T>t$.

This assumption of conditional lognormality of the real marginal rates of substitution, and of conditional normality of the inflation rates, leads to exact and simple expressions for the premia. Conditional lognormality of real marginal rates of substitution follows from conditional normality of consumption growth rates under the assumption of constant relative risk aversion. Conditional lognormality, counter to unconditional lognormality, is not a very restrictive assumption. The parameters (means and covariances) of the

5 Specific assumptions about the nominal and real marginal rate of substitution then leads to specific theories of the term structure of interest rate, as for instance in Cox, Ingersoll and Ross (1981). 
distributions are not assumed to be constant but may be time- and state-dependent. The increments to the $\log$ of the variables need not be independent but may be serially correlated.

Under assumptions (A1a) and (A2) the nominal term premium fulfills (see Appendix for details)

$$
\varphi\left(t, t^{\prime}, T\right)=-\frac{1}{2} \operatorname{Var}_{l}\left[i\left(t^{\prime}, T\right)\right]\left(T-t^{\prime}\right)-\operatorname{Cov}_{t}\left[\dot{m}\left(t, t^{\prime}\right), \dot{m}\left(t^{\prime}, T\right)\right] /\left(T-t^{\prime}\right),
$$

where $\bar{m}(t, T) \equiv \ln [\mathscr{K}(t, T) P(t) / P(T)] \equiv m(t, T)-[p(T)-p(t)]$ is the log nominal marginal rate of substitution, $m(t, T) \equiv \ln \mathscr{K}(t)$ is the $\log$ real marginal rate of substitution, and $p(t)$ $\equiv \ln P(t)$ is the log price level. The nominal term premium is the sum of two terms: the negative of half the variance of the future spot rate multiplied with its maturity, and the negative of the covariance between the log of the nominal marginal rate of substitution between times $t$ and $t^{\prime}$ and the log of the nominal marginal rate of substitution between $t^{\prime}$ and $T\left(t<t^{\prime}<T\right)$, divided by the maturity $T-t^{\prime}$. The first term is obviously always negative, that is, increased variance of the future spot rate by itself reduces the nominal term premium. The second term is positive or negative depending upon whether the nominal marginal rate of substitution is negatively or positively serially correlated. ${ }^{8}$ ?

In order to get some intuition for the variance term in (3.4), note that financing the

6 With the lognormality assumption as in Breeden (1986) there is no need to use the approximation $\exp (x) \approx 1+x$ as in Shiller (1990). With the approximation in Shiller the variance term in (3.4) is lost.

7 The instantaneous(-maturity) nominal term premium is given by (see Appendix for details)

$$
\begin{aligned}
& \mathcal{P}\left(t, l^{\prime}\right) \equiv \lim _{T \rightarrow l^{\prime}} \mathcal{H}\left(t, l^{\prime}, T\right) \equiv f\left(l, t^{\prime}\right)-\mathrm{E}_{t^{i}} i\left(l^{\prime}\right)= \\
& =-\operatorname{Cov}\left\{m\left(l, l^{\prime}\right)-\left\{p\left(l^{\prime}\right)-\mu(l)\right], \mu_{m}\left(t^{\prime}\right)-\mu_{p}\left(l^{\prime}\right)\right\},
\end{aligned}
$$

where $\mu_{m}\left(l^{\prime}\right)$ denotes the instantaneous mean log real marginal rate of substitution at time $l$, defined as

$$
\mu_{m}\left(l^{\prime}\right)=\lim _{T \rightarrow t^{\prime}} \mathrm{E}_{t^{\prime}}\left[m\left(l^{\prime}, T\right)\right] /\left(T-l^{\prime}\right),
$$

and where $\mu_{p}(l)$ denotes the drift of the log price level (the instantaneous mean rate of inflation at time $t^{\prime}$, defined as

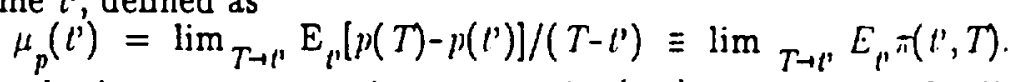

Note that the interest rate variance term in (3.4) vanishes in the limit since it is multiplied by $T-l^{\prime}$. 
forward contract by borrowing on the spot market at time $t$ ' means selling bonds at time $t^{\prime}$ at the price $p\left(t^{\prime}, T\right)$. That price is the convex function $\exp \left[-i\left(t^{\prime}, T\right)\left(T-t^{\prime}\right)\right]$ of the spot rate $i\left(l^{\prime}, T\right)$. By Jensen's inequality, for a given mean of the spot rate a higher variance of the spot rate increases the expected price of the bond to be sold. This makes the forward contract more favorable, and makes the representative investor accept a lower term premium.

In order to get some intuition for the covariance term in (3.4), note that the term can be written

$$
\begin{aligned}
& -\operatorname{Cov}_{\imath}\left[\dot{m}\left(t, t^{\prime}\right), \dot{m}\left(t^{\prime}, T\right)\right] /\left(T-t^{\prime}\right)=-\operatorname{Cov}_{\imath}\left[\dot{m}\left(t, t^{\prime}\right), \mathrm{E}_{t^{\prime}} \dot{m}\left(t^{\prime}, T\right)\right] /\left(T-t^{\prime}\right)= \\
& =-\operatorname{Cov}_{i}\left[\dot{m}\left(l, t^{\prime}\right),-i\left(t^{\prime}, T\right)\right]+\operatorname{Cov}_{l}\left[\dot{m}\left(t, t^{\prime}\right), \frac{1}{2} \operatorname{Var}_{t}{ }_{i} \dot{m}\left(t^{\prime}, T\right)\right]= \\
& =-\operatorname{Cov}_{i}\left[\dot{m}\left(t, t^{\prime}\right), \delta\left(t, t^{\prime}, T\right)-i\left(t^{\prime}, T\right)\right]+\operatorname{Cov}_{\imath}\left[\dot{m}\left(t, t^{\prime}\right), \operatorname{Var}_{l^{\prime}} \dot{m}\left(t^{\prime}, T\right)\right] \text {, }
\end{aligned}
$$

where I have used the law of iterated expectations, that $\mathrm{E}_{t^{\prime}} \bar{m}\left(t^{\prime}, T\right)=-i\left(t^{\prime}, T\right)\left(T-l^{\prime}\right)$ $\left\{\operatorname{Var}_{i} \dot{m}\left(l^{\prime}, T\right)\right.$ (see Appendix), and that $f(t, l, T)$ is known at time $t$. The first term on the right-hand side includes the negative of the covariance of the excess return on the forward contract with the log nominal marginal rate of substitution. The covariance indicates the degree of riskiness of the forward contract. If the covariance is positive (negative), the excess return on the forward contract is less (more) risky than the safe nominal return from $t$ to $l, i\left(t, t^{\prime}\right)$ (which has zero covariance with the log nominal marginal rate of substitution since it is known at $t$ ). A forward contract less (more) risky than a safe nominal return contributes to investors' accepting a negative (positive) expected excess return and hence a negative (positive) term premium. ${ }^{8}$ (This argument can of course also be expressed in terms of the riskiness of the holding period return in (2.9), the riskiness of holding a long bond that matures at time $T$ from time $l$ to time $t$ ' instead of a bond that matures at time $t^{\prime}$.)

The covariance term in (3.4) can be studied further by specific assumptions about the

8 Note that a safe nominal return is not safe in utility terms, since the nominal marginal rate of substitution is stochastic. Therefore a stochastic nominal return can be less risky (in utility terms) than a safe nominal return. 
marginal rate of substitution. The frequent assumption of a time-separable utility function for the representative investor with constant relative risk aversion and constant rate of time preference results in the log real marginal rate of substitution fulfilling

$$
m(t, T)=-\gamma[\alpha T)-\alpha(t)]-\rho(T-t), \quad \gamma \geq 0, \rho>0,
$$

where $c(t)$ denotes the $\log$ of the representative investor's real consumption at time $t, \gamma$ is the coefficient of relative risk aversion, and $\rho$ is the rate of time preference.

Under assumption (A3) the second term in (3.4) can be written

$$
\begin{gathered}
-\operatorname{Cov}_{l}\left[\bar{m}\left(t, t^{\prime}\right), \dot{m}\left(t^{\prime}, T\right)\right] /\left(T-t^{\prime}\right)= \\
=-\operatorname{Cov}_{i}\left\{\gamma\left[c\left(t^{\prime}\right)-c(t)\right] /\left(t^{\prime}-t\right)+\pi\left(t, t^{\prime}\right), \gamma\left[c(T)-c\left(t^{\prime}\right)\right] /\left(T-t^{\prime}\right)+\pi\left(t^{\prime}, T\right)\right\}\left(t^{\prime}-t\right) .
\end{gathered}
$$

The term is proportional to the negative of the covariance between the sum of $\gamma$ times real consumption growth and the inflation rate from time $t$ to $t^{\prime}$ and the same sum from time $t^{\prime}$ to $T$. (Recall that $\pi\left(t, t^{\prime}\right)$ is the average inflation rate from time $t$ to time $t^{\prime}>t$, defined as $\pi\left(t, t^{\prime}\right) \equiv\left[p\left(t^{\prime}\right)-p(t)\right] /\left(t^{\prime}-t\right)$

We also observe that in the special case of $?=1$, that is, of the log utility function, (3.6) equals

$$
-\operatorname{Cov}_{i}\left\{\left[p\left(t^{\prime}\right)+c\left(t^{\prime}\right)\right]-[p(l)+c(t)],[p(T)+c(T)]-\left[p\left(t^{\prime}\right)+c\left(t^{\prime}\right)\right]\right\} /\left(T-t^{\prime}\right) .
$$

This term is simply proportional to the negative of the covariance between the growth rate for nominal consumption between times $t$ and $t^{\prime}$ and the same growth rate between times $t$ and $T$. Thus, for the log utility function, monetary policies that target nominal consumption or nominal GNP (argued for the US by McCallum, for instance in McCallum (1990)) have direct implications for the nominal term premium. If such targeting is period by period, with fairly short periods, and if each period is targeted independently of the outcome in previous periods (that is, accepting base drift), the outcome may be serially uncorrelated nominal consumption growth rates, resulting in a zero covariance term for the nominal term premium. If the targeting is for longer periods without accepting base drift, mean reversion arises in nominal consumption growth rates, and nominal consumption growth becomes negatively serially correlated, having a positive 
effect on the nominal term premium. If the targeting is successful in the sense that variability of the nominal consumption growth rate is small, the covariance will in any case be small and have only a small effect on the nominal term premium. ${ }^{9}$

Below I will also need the real (forward) tern premium, $\psi\left(t, t^{\prime}, T\right)$, defined as

$$
\psi\left(t, t^{\prime}, T\right) \equiv g\left(t, t^{\prime}, T\right)-\mathrm{E}_{i} r\left(t^{\prime}, T\right) .
$$

Under the assumption that the real price $q(l, T)$ of a real discount bond is determined by the expected real marginal rate of substitution,

$$
x(t, T)=\mathrm{E}_{\boldsymbol{t}} \mathcal{K}(t, T)
$$

and the assumption of lognormality of the real marginal rate of substitution, (A2), the real term premium can be written

$$
\psi\left(t, t^{\prime}, T\right)=-\frac{1}{2} \operatorname{Var}\left[r\left(t^{\prime}, T\right)\right]\left(T-l^{\prime}\right)-\operatorname{Cov}_{l^{\prime}}\left[m\left(t, t^{\prime}\right), m\left(t^{\prime}, T\right)\right] /\left(T-t^{\prime}\right)
$$

The real term premium is the sum of two terms: the negative of half the variance of the expected future real interest rate times its maturity $T-t$, and the negative of the covariance between the log of the real marginal rate of substitution between times $t$ and $t^{\prime}$ and the same $\log$ between times $t^{\prime}$ and $T$, divided by $T-t^{\prime}$. Equation (3.9) is of course a special case of (3.4), namely when the price level is constant. The intuition for the variance and covariance term in (3.9) is analogous to the intuition for the terms in (3.4).

Under assumption (A3) the second term in (3.9) can be written

$$
-\operatorname{Cov}_{t}\left[m\left(t, t^{\prime}\right), m\left(t^{\prime}, T\right)\right] /\left(T-t^{\prime}\right)=-\gamma^{2} \operatorname{Cov}_{l}\left[c\left(t^{\prime}\right)-c(l), c(T)-c\left(t^{\prime}\right)\right] /\left(T-t^{\prime}\right),
$$

which is proportional to the negative of the covariance between consumption growth rate from $t$ to $t$ ' and the consumption growth rate from $t^{\prime}$ to $T$. Whether the second term in (3.9) contributes negatively or positively to the real term premium then depends on

9 Under assumption (A3) the instantaneous nominal term premium fulfills (see Appendix)

$$
\varphi\left(t, t^{\prime}\right)=-\operatorname{Cov}_{t}\left\{\gamma c\left(t^{\prime}\right)+\nu\left(t^{\prime}\right), \gamma \mu_{c}\left(t^{\prime}\right)+\mu_{p}\left(t^{\prime}\right)\right\},
$$

where $\mu_{r}(l)$ denotes the drift of the log consumption level, defined by

$$
\mu_{c}\left(t^{\prime}\right)=\lim _{T \rightarrow t^{\prime}} \mathrm{E}_{p},\left[\left((T)-c\left(l^{\prime}\right)\right] /\left(T-l^{\prime}\right)\right.
$$

(note that $\mu_{m}(l)=-\gamma \mu_{c}\left(l^{\prime}\right)-p$ under $(\mathrm{A} 3)$ ). 
whether real consumption growth is positively or negatively serially correlated. ${ }^{10}$

\section{Inflation Risk Premia}

In order to relate forward rates to expected future inflation rates, I first need to specify the relevant inflation risk premia. The forward inflation risk premium, $\theta\left(t, t^{\prime}, T\right)$, is defined as the excess of the difference between expected future nominal and real interest rates over the expected future inflation rate,

$$
\theta\left(t, t^{\prime}, T\right) \equiv \mathrm{E}_{\imath} i\left(t^{\prime}, T\right)-\mathrm{E}_{\imath}\left(t^{\prime}, T\right)-\mathrm{E}_{\imath} \pi\left(t^{\prime}, T\right)
$$

The standard (spot) inflation risk premium is give by $\theta(t, l, T) \equiv i(t, T)-r(t, T)-$ $E_{t} \pi(t, T)$, that is, when $t$ and $t^{\prime}$ coincide. The inflation premium can be interpreted as the expected real excess return on a nominal bond from time $t^{\prime}$ to maturity time $T$ over a real bond from time $t^{\prime}$ to maturity time $T$.

Under assumptions (A1) and (A2) the forward inflation risk premium fulfills (see Appendix for details) $\mathfrak{}$

$$
\alpha\left(t, l^{\prime}, T\right)=-\frac{1}{2} \operatorname{Var}_{l}\left[\pi\left(l^{\prime}, T\right)\right]\left(T-l^{\prime}\right)+\operatorname{Cov}_{t}\left[m\left(l^{\prime}, T\right), \pi\left(t^{\prime}, T\right)\right] .
$$

The forward inflation risk premium is the sum of two terms: the negative of half the variance of the future inflation rate from time $t^{\prime}$ to time $T$ multiplied by $T$ - $t^{\prime}$, and the covariance between the real future marginal rate of substitution between times $t^{\prime}$ and $T$ and the inflation rate from $t^{\prime}$ to $T .1213$

10 The instantaneous(-maturity) real term premium is given by

$$
\psi\left(t, t^{\prime}\right) \equiv \lim _{T \rightarrow t^{\prime}} \psi\left(t, t^{\prime}, T\right) \equiv g\left(t, t^{\prime}\right)-\mathrm{E}_{t^{\prime}}\left(l^{\prime}\right)=-\operatorname{Cov}_{t^{\prime}}\left[m\left(t, t^{\prime}\right), \mu_{m}\left(l^{\prime}\right)\right\}
$$

Under assumption (A3) it fulfills

$$
\psi\left(t, l^{\prime}\right)=-\gamma^{2} \operatorname{Cov}{ }_{l}\left[\left(l^{\prime}\right), \mu_{l}\left(l^{\prime}\right)\right]
$$

11 As explained in the Appendix, the expression (4.2) is under the assumption that the spot inflation premium $O\left(l^{\prime}, l^{\prime}, T\right)$ at time $l^{\prime}$ is a deterministic function of $l^{\prime}$ and information available at time $\ell$. Without this assumption, $\mathrm{Var}_{\text {, }}$ and $\mathrm{Cov}_{t}$ in (4.2) are replaced by $\mathrm{E}_{\boldsymbol{t}} \operatorname{Var}_{\boldsymbol{t}^{\prime}}$ and $\mathrm{E}_{\boldsymbol{t}} \operatorname{Cov}_{\boldsymbol{t}^{\prime}}$.

12 In order to get an idea of how the lognormality assumption simplifies the expression for the inflation risk premium, we can compare with the cumbersome expression Benninga and Protopapadakis (1983) derive without using the lognormality assumption (notation 
Thus, increased variance of the inflation rate by itself reduces the inflation risk premium. In order to get some intuition for that, note that the real return on the nominal bond varies with the ratio of price levels $P\left(l^{\prime}\right) / P(T)$ which is a convex function $\exp \left[-\pi\left(t^{\prime}, T\right)\left(T-t^{\prime}\right)\right]$ of the inflation rate between time $t^{\prime}$ and time $T$. By Jensen's inequality, for a given mean inflation rate a higher variance of the inflation rate will increase the expected ratio of price levels. This makes investment in the nominal bond more attractive and makes the representative investor accept a lower inflation risk premium.

In order to get some intuition for the covariance term, we note that the inflation rate is the excess real rate of return on real bonds over nominal bonds. If the covariance of that excess real rate of return with the log real marginal rate of substitution is positive

modified to coincide with that of this paper):

$$
\begin{gathered}
{[1+i(t, T)] /[1+i(t, T)] \equiv \exp \{[i(t, T)-r(t, T)](T-t)\}=} \\
=1 /\left\{\mathrm{E}_{t}[P(t) / P(T)]+[1+r(t, T)] \operatorname{Cov}_{l}[\mathscr{K}(t, T) P(t) / P(T), P(t) / P(T)]\right\},
\end{gathered}
$$

where $\bar{i}(t, T)$ and $\bar{r}(t, T)$ are simple $(T-l)$-period interest rates.

13 The instantaneous-(maturity) forward inflation risk premium, $\delta\left(l, t^{\prime}\right)$, is given by

$$
\theta\left(t, t^{\prime}\right) \equiv \lim _{T \rightarrow l^{\prime}} \theta\left(t, l^{\prime}, T\right) \equiv \mathrm{E}_{l^{\prime}} i\left(l^{\prime}\right)-\mathrm{E}_{l^{\prime}}\left(l^{\prime}\right)-\mathrm{E}_{l^{\prime}} m_{m}\left(l^{\prime}\right)=-\frac{1}{2} \sigma_{p}^{2}\left(t, l^{\prime}\right)+\sigma_{m p}\left(t, l^{\prime}\right),
$$

where $\sigma_{p}^{2}\left(t, l^{\prime}\right)$ is the expected future instantaneous rate of variance of the log price level, defined as

$$
\sigma_{p}^{2}\left(t, t^{\prime}\right) \equiv \mathrm{E}_{l^{\prime}} \lim _{T \rightarrow t^{\prime}}, \operatorname{Var}_{p^{\prime}}\left[p(T)-p\left(l^{\prime}\right)\right] /\left(T-l^{\prime}\right)
$$

and where $\sigma_{m p}\left(t, l^{\prime}\right)$ is the expected future instantaneous rate of covariance between the log real marginal rate of substitution and the log price level, defined as

$$
\sigma_{m p}\left(t, t^{\prime}\right) \equiv \mathrm{E}_{l} l^{\lim } T \rightarrow t^{\prime} \operatorname{Cov}_{l^{\prime}}\left[m\left(t^{\prime}, T\right), p(T)-p\left(t^{\prime}\right)\right] /\left(T-l^{\prime}\right)
$$

Under assumption (A3) the latter fulfills

$$
\sigma_{m p}\left(t, l^{\prime}\right)=-\gamma \sigma_{(p)}\left(t, l^{\prime}\right)
$$

where $\sigma_{c p}\left(t, t^{\prime}\right)$ is the expected future instantaneous rate of covariance between $\log$ consumption and the log price level. The instantaneous spot inflation risk premium is then

as in Fischer (1975) and Breeden (1986)

$$
O(l, l)=-\frac{1}{2} \sigma_{p}^{2}(l, l)-\gamma \sigma_{c p}(l, t)
$$

Park (1989) gives an elegant derivation of a finite-maturity inflation risk premium with the lognormality assumption in a cash-in-advance model so that money demand fulfills the quantity equation. 
(negative), the real bonds are less (more) risky than nominal bonds, which contributes to a positive (negative) inflation risk premium.

Under assumption (A3) the second term in (4.2) can be written

$$
-\gamma \operatorname{Cov}_{i}\left\{c(T)-c\left(t^{\prime}\right), \pi\left(t^{\prime}, T\right)\right\}
$$

which is proportional to the negative of the covariance between real consumption growth and inflation.

\section{Forward Rates and Expected Future Inflation Rates}

I examined above the first issue mentioned in the Introduction, namely, to what extent forward rates indicate expected future interest rates. The second issue is to what extent forward rates indicate expected future inflation rates. Let me therefore first examine the difference between the forward rate and the expected future inflation.

From the definition of the term premium in (3.1) and the forward inflation premium in (4.1) it follows that the difference can be written

$$
f\left(t, t^{\prime}, T\right)-\mathrm{E}_{t} \pi\left(t^{\prime}, T\right)=\mathrm{E}_{t}\left(t^{\prime}, T\right)+\varphi\left(t, t^{\prime}, T\right)+O\left(t, t^{\prime}, T\right),
$$

the sum of the expected future real interest rate, the nominal term premium and the forward inflation premium. The determinants of the nominal term premium were discussed in section III and the determinants of the inflation premium in section IV. Since the nominal term premium depends on the serial correlation of the real marginal rate of substitution and inflation between the nonoverlapping periods from time $t$ to $t^{\prime}$ and from time $l$ to $T$, whereas the forward inflation premium depends on the covariance between the real marginal rate substitution and inflation for the period from time $t^{\prime}$ to $T$, there is no scope for further simplification of the last two terms in (5.1).

Use of the forward rate to indicate expected future inflation must hence be conditional upon the expected future real interest rate, which must therefore be explicitly assumed or estimated separately. If however real forward rates are available, that is, if there is a well functioning market in real bonds for different maturities so a real yield curve is available, 
these real forward rates can exploited. Let me therefore consider to what extent the difference between the nominal and real forward rates indicates the expected future inflation rate. From the definitions of the nominal and real term premia in (3.1) and (3.8), and of the forward inflation premium in (4.1), it follows that the difference between the nominal and real forward rates exceed the expected future inflation rate by

$$
f\left(t, t^{\prime}, T\right)-\not{g}\left(l, t^{\prime}, T\right)-\mathrm{E}_{t} \pi\left(t^{\prime}, T\right)=\left[\left(t\left(t, t^{\prime}, T\right)-\psi\left(t, t^{\prime}, T\right)\right]+\not\left(t, t^{\prime}, T\right),\right.
$$

the sum of the difference between the nominal and the real term premium and the forward inflation premium. 14

The difference between the nominal and real term premium is

$$
\begin{gathered}
\left(t, l^{\prime}, T\right)-\psi\left(l, l^{\prime}, T\right)= \\
=-\frac{1}{2}\left\{\operatorname{Var}_{l}\left[l\left(l^{\prime}, T\right)\right]-\operatorname{Var}_{l}\left[l\left(l, T^{\prime}\right)\right]\right\}\left(T-l^{\prime}\right) \\
-\left\{\operatorname{Cov}_{l}\left[m\left(l, l^{\prime}\right), m\left(l^{\prime}, T^{\prime}\right)\right]-\operatorname{Cov}_{l}\left[m\left(l, l^{\prime}\right), m\left(l^{\prime}, T\right)\right]\right\} /\left(T-l^{\prime}\right) .
\end{gathered}
$$

It obviously depends on the difference between the variances of the nominal and real future interest rates and the difference between the serial correlation of the nominal and the real marginal rates of substitution. As above, with assumption (A3) the second term in (5.3) can be expressed in terms of consumption growth rates and inflation.

\section{Foreign Term Premia and Foreign Exchange Risk Premia}

The third issue is to what extent the difference between domestic and foreign nominal forward rates indicate differences in the expected future domestic and foreign nominal interest rates. For that issue I need to define the (nominal) foreign currency interest rate, forward rate and term premium. These definitions are analogous to the definitions of the corresponding domestic currency variables:

Let $Q^{*}(l, T)$ denote the foreign currency price at time $t$ of a foreign currency pure discount bond that matures at time $T$ and then pays one unit of foreign currency. Then

14 Ben-Shahar and Cukierman (1973), Paunio and Suvanto (1977), Woodward (1990), Yariv (1990), and Bank of England (1993) use market interest rates on indexed bonds and nominal bonds to infer inflation expectations. 
the (nominal) foreign currency interest rate $\imath^{*}(l, T)$ is defined by the relation

$$
Q^{*}(t, T) \equiv \exp \left[-\imath^{*}(\iota, T)(T-l)\right], \text { or } i^{*}(\iota, T)=-\ln \left[Q^{*}(t, T)\right] /(T-t) .
$$

The (nominal) foreign currency forward rate, $f^{*}\left(t, t^{\prime}, T\right)$, is defined by

$$
f^{*}\left(t, t^{\prime}, T\right) \equiv\left[\imath^{*}(t, T)(T-t)-\imath^{*}\left(t, t^{\prime}\right)\left(t^{\prime}-t\right)\right] /\left(T-t^{\prime}\right) .
$$

The (nominal) foreign currency term premium is defined as

$$
\varphi^{*}\left(t, t^{\prime}, T\right) \equiv f^{*}\left(t, t^{\prime}, T\right)-\mathrm{E}_{t} \imath^{*}\left(l^{\prime}, T\right) .
$$

In order to specify the determinants of the nominal foreign term premium I make the analog assumption to (A1a), namely that the foreign currency bond is priced according to $\left(\mathrm{A} 1 \mathrm{a}^{\prime}\right)$

$$
Q^{*}(t, T)=\mathrm{E}_{\imath}\left[\mathscr{K}^{*}(t, T) P^{*}(t) / P^{*}(T)\right]
$$

where $\mathscr{K}^{*}(t, T)$ denotes a representative investor's foreign real marginal rate of substitution and $P^{*}(t)$ denotes the foreign price level. Then the right-hand side is the expected foreign investor's foreign currency marginal rate of substitution. Then the same analysis of the determinants of the foreign term premium can be undertaken as in section III, with the substitution everywhere of the foreign interest rate, real marginal rate of substitution, consumption, price level and money supply for the corresponding domestic variables.

The issue of to what extent the difference between nominal domestic and foreign currency forward rates indicate differences between expected future domestic and foreign interest rates is then straightforward. By the definition of the domestic and foreign nominal term premia, we simply have

$$
\left[f\left(t, t^{\prime}, T\right)-f^{*}\left(t, t^{\prime}, T\right)\right]-\left[\mathrm{E}_{i} i(l, T)-\mathrm{E}_{\imath} \imath^{*}(l, T)\right]=\varphi\left(t, t^{\prime}, T\right)-\psi^{*}\left(t, t^{\prime}, T\right),
$$

the difference between the domestic and foreign nominal term premia.

According to the analysis above, under assumptions (A3) and (A4) the difference in the term premia will depend on the degree of risk aversion in the two countries, whether the price levels are pro- or countercyclical, and the serial correlation of consumption growth rates. If the countries are not very different in these respects, the difference between the domestic and foreign nominal term premia are likely to be small. Then the 
difference between the forward rate curves is a precise measure of the expected future interest rate differential.

The fourth issue is to what extent the difference between domestic and foreign forward rates indicates expected future domestic currency depreciation rates. For this issue I need to define and specify the foreign exchange risk premium.

The (nominal) forward foreign exchange risk premium, $\xi\left(t, t^{\prime}, T\right)$, is defined as

$$
\xi\left(t, t^{\prime}, T\right) \equiv \mathrm{E}_{t} i\left(t^{\prime}, T\right)-\mathrm{E}_{\imath} \imath^{*}\left(t^{\prime}, T\right)-\mathrm{E}_{t} \delta\left(l^{\prime}, T\right),
$$

the excess of expected future interest rate differential over the expected future domestic currency depreciation rate (recall that $\delta\left(t, t^{\prime}\right) \equiv\left[s\left(t^{\prime}\right)-s(t)\right] /\left(t^{\prime}-t\right)$, where $s(t) \equiv \ln S(t)$ denotes the log exchange rate). The foreign exchange risk premium can be interpreted as the expected nominal excess return on domestic bonds over foreign bonds. ${ }^{15}$

From the definitions of the domestic and foreign currency term premium in (3.1) and (6.3) and the above definition of the forward foreign exchange risk premium it follows that the excess of the difference between the domestic and foreign currency forward rates over the expected future domestic currency depreciation rate is

$$
\left[f\left(t, t^{\prime}, T\right)-f^{*}\left(t, t^{\prime}, T\right)\right]-\mathrm{E}_{l} \delta\left(t^{\prime}, T\right)=\left[\phi\left(t, t^{\prime}, T\right)-\varphi^{*}\left(l, t^{\prime}, T\right)\right]+\xi\left(t, l^{\prime}, T\right),
$$

the sum of the difference between the domestic and foreign nominal term premia and the forward foreign exchange risk premium.

In order to derive the determinants of the forward foreign exchange risk premium, the nominal foreign discount bond is assumed to priced not only according to (A1a') but also according to

$$
Q^{*}(t, T)=E_{1}\{\mathscr{K}(t, T)[P(i) / P(T)][S(T) / S(t)]\}
$$

Here the expression between the curly brackets is a representative investor's foreign currency marginal rate of substitution, that is, the representative investor's marginal rate

15 In the recent literature on exchange rate target zones the foreign exchange rate premium has been disregarded. Svensson (1992) argues that this is warranted for narrow target zones, even if there is realignment risk. 
of substitution of foreign currency at time $T$ for foreign currency at time $t .16$

Under assumption (A5) and (A2), conditional lognormality (extended to include the exchange rate), the forward foreign exchange risk premium fulfills (see Appendix for details) ${ }^{17}$

$$
\xi\left(l, l^{\prime}, T\right)=\frac{1}{2} \operatorname{Var}\left[\delta\left(l^{\prime}, T\right)\right]\left(T-l^{\prime}\right)+\operatorname{Cov}_{l}\left[m\left(l^{\prime}, T\right), \delta\left(t^{\prime}, T\right)\right] .
$$

The forward foreign exchange risk premium is the sum of two terms: half the rate of variance of the currency depreciation rate from $l^{\prime}$ to $T$ multiplied by $T-t^{\prime}$, and the covariance between the domestic currency marginal rate of substitution between times $t^{\prime}$ and $T$ and the domestic currency depreciation rate from $t^{\prime}$ to $T$. 18

In order to get some intuition for the variance term, we first note that it enters with a positive sign in the foreign exchange risk premium, in contrast to the case for the term and inflation risk premia. Increased variance of the currency depreciation rate by itself increases the foreign exchange risk premium. The reason is that the domestic currency

16 The representative investor's real foreign marginal rate of substitution $\mathscr{K}^{*}(t, T)$ and the real (domestic) marginal rate of substitution $\mathcal{K}(t, T)$ fulfill $\mathcal{K}^{*}(t, T)\left[P^{*}(t) / P^{*}(T)\right]=$ $\mathscr{K}(t, T)[P(t) / P(T)][S(T) / S(t)]$. Then $\left(\mathrm{Ala}^{\prime}\right)$ and (Ala") are consistent.

17 As explained in the Appendix, the expression (6.7) is under the assumption that the spot foreign exchange risk premium $\xi\left(l^{\prime}, l^{\prime}, T\right)$ at time $t^{\prime}$ is a deterministic function of $l^{\prime}$ and information available at time $t$. Without this assumption, $\mathrm{Var}_{t}$ and $\mathrm{Cov}_{t}$ in (6.7) are replaced by $\mathrm{E}_{t} \mathrm{Var}_{l}$, and $\mathrm{E}_{l} \mathrm{Cov}_{l}$.

18 The instantaneous(-maturity) forward foreign exchange risk premium, $\xi\left(l, l^{\prime}\right)$,

$$
\begin{aligned}
& \xi\left(l, l^{\prime}\right) \equiv \lim _{T \rightarrow l^{\prime}} \xi\left(l, l^{\prime}, T\right) \equiv E_{l^{i}} i\left(l^{\prime}\right)-\mathrm{E}_{t^{i^{*}}\left(l^{\prime}\right)-\mathrm{E}_{t^{\prime}}{ }_{s}\left(l^{\prime}\right)=} \\
& =\frac{1}{2} \sigma_{s}^{2}\left(l, l^{\prime}\right)+\sigma_{m s}\left(t, t^{\prime}\right)-\sigma_{p s}\left(t, t^{\prime}\right),
\end{aligned}
$$

where $\mu_{s}\left(l^{\prime}\right)$ is the drift of the log exchange rate (the instantanenous expected rate of currency depreciation) $\left[\equiv \lim T \rightarrow l^{\prime} E_{\ell}, \delta(l, T)\right], \sigma_{S}^{2}\left(t, l^{\prime}\right)$ is the expected future instantaneous rate of variance of the log exchange rate, $\sigma_{m, s}\left(l, t^{\prime}\right)$ is the expected future instantaneous rate of covariance between the log real marginal rate of substitution and the log exchange rate, and $\sigma_{p s}\left(l, l^{\prime}\right)$ is the expected future instantaneous rate of covariance between the log price level and the log exchange rate.

The instantaneous spot foreign exchange risk premium is under assumption (A3)

$$
\xi(l)=\frac{1}{2} \sigma_{s}^{2}(l)-\gamma \sigma_{c s}(l)-\sigma_{p s}(t),
$$

which is consistent with previous derivations (cf. Adler and Dumas (1983), Engel (1992), Fama and Farber (1979), Hodrick (1987), Roll and Solnik (1979) and Stulz (1981, 1984)). 
return on foreign bonds varies with the ratio of exchange rates $S(T) / S\left(t^{\prime}\right)$. This ratio is a convex function $\exp \left[\delta\left(t^{\prime}, T\right)\left(T-t^{\prime}\right)\right]$ of the currency depreciation rate. For a given expected depreciation rate a higher variance of the depreciation rate increases the expected ratio, which makes foreign bonds a more attractive investment than domestic bonds. This contributes to the representative investor demanding a higher foreign exchange risk premium. ${ }^{19}$

In order to understand the covariance term, note that the currency depreciation rate is the nominal excess rate of return on foreign currency bonds over domestic currency bonds. If the covariance with that excess rate of return with the log nominal marginal rate of substitution is positive (negative), foreign currency bonds are less (more) risky than domestic currency bonds. This contributes to the representative investor demanding a positive (negative) foreign exchange risk premium.

Under assumption (A3) the second term in (6.7) can be written

$$
-\operatorname{Cov}_{i}\left\{\gamma\left[d(T)-d\left(t^{\prime}\right)\right] /\left(T-t^{\prime}\right)+\pi\left(t^{\prime}, T\right), \delta\left(t^{\prime}, T\right)\right]\left(T-l^{\prime}\right)
$$

which can be subject to empirical estimation.

The fifth and final issue is to what extent the difference between domestic and foreign currency forward rates indicates the expected difference between future domestic and foreign inflation rates. From (5.1) and its foreign currency analog follows directly that the excess of the difference between the forward rates over the difference in expected future inflation rates fulfills

$$
\begin{gathered}
{\left[\int\left(l, l^{\prime}, T\right)-f^{*}\left(l, l^{\prime}, T\right)\right]-\left[\mathrm{E}_{\imath} \pi\left(l^{\prime}, T\right)-\mathrm{E}_{l} \pi^{*}\left(l^{\prime}, T\right)\right]=} \\
=\left[\mathrm{E}_{\imath} r\left(l^{\prime}, T\right)-\mathrm{E}_{l} \imath^{*}\left(l^{\prime}, T\right)\right]+\left[\vartheta\left(l, l^{\prime}, T\right)-\nu^{*}\left(l, l^{\prime}, T\right)\right]+\left[\alpha\left(l, l^{\prime}, T\right)-\theta^{*}\left(l, l^{\prime}, T\right)\right],
\end{gathered}
$$

the sum of the difference between expected future domestic and foreign real interest rates,

19 The variance term in (6.7) does $n o l$ imply a Siegel-type paradox in the foreign exchange risk premium. Let $S^{*}(t) \equiv 1 / S(l), \delta^{*}\left(l^{\prime}, T\right) \equiv-\delta\left(l^{\prime}, T\right)$ and $m^{*}\left(l^{\prime}, T\right) \equiv m\left(l^{\prime}, T\right)$ $\delta\left(l^{\prime}, T\right)$. Then it is easy to see that the foreign exchange risk premium from the foreign country's point of view fulfills $\xi^{*}\left(l, l^{\prime}, T\right) \equiv \mathrm{E}_{i} i^{*}\left(l^{\prime}, T\right)-\mathrm{E}_{t} i\left(l^{\prime}, T\right)-\mathrm{E}_{t^{*}}\left(l^{\prime}, T\right) \equiv-\xi\left(l, l^{\prime}, T\right)=$ $\frac{1}{2} \operatorname{Var}_{l}\left[\delta^{*}\left(t^{\prime}, T\right)\right]\left(T-l^{\prime}\right)+\operatorname{Cov}_{l}\left[\tilde{m}^{*}\left(l^{\prime}, T\right), \delta^{*}\left(l^{\prime}, T\right)\right]$. 
the difference between the domestic and foreign currency term premia, and the difference between the domestic and foreign forward inflation risk premia. If the premia have the same sign and same order of magnitude in the domestic and foreign country, they will obviously tend to cancel.

In passing, we note that in analogy with the nominal forward foreign exchange risk premium defined in (6.5) we can define a real forward foreign exchange risk premium $\zeta(t, t, T)$ according to

$$
\zeta\left(t, t^{\prime}, T\right) \equiv \mathrm{E}_{t} r\left(t^{\prime}, T\right)-\mathrm{E}_{t} r^{*}\left(t^{\prime}, T\right)-\mathrm{E}_{t} \kappa\left(t^{\prime}, T\right),
$$

the difference between the domestic and foreign expected future real interest rates and the expected future real currency depreciation rate, $\mathrm{E}_{t} \kappa\left(t^{\prime}, T\right)$. Here the real currency depreciation rate, the rate of change of the real exchange rate, is defined as

$$
\kappa\left(l^{\prime}, T\right) \equiv \delta\left(l^{\prime}, T\right)+\pi\left(l^{\prime}, T\right)-\pi^{*}\left(l^{\prime}, T\right),
$$

the nominal currency depreciation rate adjusted for the inflation rate difference. The real foreign exchange risk premium is not independent of the risk premia already defined; substitution of (4.1), its foreign analog, and (6.5) into (6.10) results in

$$
\zeta\left(t^{\prime}, T\right) \equiv \xi\left(t^{\prime}, T\right)-\left[0\left(t, t^{\prime}, T\right)-0^{*}\left(t, t^{\prime}, T\right)\right] .
$$

The real foreign exchange risk premium is identical to the nominal forward foreign exchange risk premium less the difference between the domestic and foreign forward inflation risk premia.

Even if expected Purchasing Power Parity holds, in the sense that $\mathrm{E}_{t} r\left(l^{\prime}, T\right)=0$, the expected future domestic and foreign real interest rates may differ, unless the nominal foreign exchange risk premium equals the difference between the domestic and foreign inflation risk premia.

\section{Estimation of the Premia}

The different risk premia can be estimated in two different ways, under the maintained assumption of rational expectations. The first way is simply to regress the 
relevant excess return on variables in the information set, without relying on any particular asset pricing model. The second way is to rely on a particular asset pricing model to derive expressions for the risk premia and then estimate these expressions.

The first way is straightforward. Recall (3.1), the definition of the nominal term premium as the difference between the forward rate and the expected future spot rate, $\varphi\left(t, t^{\prime}, T\right) \equiv f\left(t, t^{\prime}, T\right)-\mathrm{E}_{t} i\left(t^{\prime}, T\right)$. The expected future spot rate is not observed. However, under rational expectations the realized future spot rate differs from the expected future spot rate by an error term that is uncorrelated with date $t$ information,

$$
i\left(l^{\prime}, T\right)=\mathrm{E}_{i} i\left(l^{\prime}, T\right)+\epsilon\left(l^{\prime}\right), \quad \mathrm{E}_{t} \epsilon\left(l^{\prime}\right)=0 .
$$

It follows that the realized excess return on a forward contract differs from the nominal term premium by the negative of the error term,

$$
f\left(t, t^{\prime}, T\right)-i\left(t^{\prime}, T\right) \equiv \varphi\left(t, t^{\prime}, T\right)-\epsilon\left(t^{\prime}\right) .
$$

Regression of the excess return on variables in the time $t$ information set will then result in an estimate of a time-varying conditional nominal term premium. Regressing the excess return on a constant will result in an estimate of the unconditional nominal term premium, the average conditional nominal term premium.

Similarly, the real term premium can be estimated by regression of the realized excess return on a real forward contract, $x\left(t, l^{\prime}, T\right)-1\left(t^{\prime}, T\right)$, on variables in the time $t$ information set. This requires observations of real interest rates on a market for real bonds, though. The inflation risk premium can be estimated by regression of the realized excess return on on a nominal bond over a real bond, $i\left(l^{\prime}, T\right)-r\left(l^{\prime}, T\right)-\pi\left(l^{\prime}, T\right)$. This also requires observations of real interest rates on real bonds. Without a market for real bonds the real term premium and the inflation risk premium can hence not be estimated in this direct way.

The foreign exchange risk premium can be estimated by regression of the realized excess return on domestic bonds over foreign bonds, $i\left(t^{\prime}, T\right)-i^{*}\left(t^{\prime}, T\right)-\delta\left(t^{\prime}, T\right)$.

The second way to estimate the risk premia is to rely on the expressions derived under 
the asset pricing assumption (Ala,b) and the conditional lognormality assumption (A2). For the nominal term premium, this is expression (3.4), repeated here as

$$
\varphi\left(t, t^{\prime}, T\right)=-\frac{1}{2} \operatorname{Var}_{l}\left[i\left(t^{\prime}, T\right)\right]\left(T-t^{\prime}\right)-\operatorname{Cov}_{t}\left[\dot{m}\left(t, t^{\prime}\right), \dot{m}\left(t^{\prime}, T\right)\right] /\left(T-t^{\prime}\right) .
$$

Assuming a particular asset pricing model means specifying the log nominal marginal rate of substitution, $\bar{m}\left(l, t^{\prime}\right)$. The assumption (A3) of constant relative risk aversion implies

$$
\bar{m}\left(t, t^{\prime}\right) \equiv m\left(t, t^{\prime}\right)-\pi\left(t, t^{\prime}\right)\left(t^{\prime}-t\right)=-\gamma\left[\alpha\left(t^{\prime}\right)-\alpha(t)\right]-\rho\left(t^{\prime}-t\right)-\pi\left(t, t^{\prime}\right)\left(t^{\prime}-t\right) .
$$

This expression can then be substituted into the covariance term in the right-hand side of (7.3), resulting in the expression (3.6). Conditional upon a given coefficient of relative risk aversion $\gamma>0$, and with time series data on consumption and inflation, a time-varying conditional term premium can be estimated with the General Method of Movements as in Harvey (1989). The unconditional term premium can be estimated by computing the sample moments of the right-hand side of (7.3).

The real term premium, the inflation risk premium and the foreign exchange risk premium can be estimated along the same line. The real term premium and the inflation risk premium can be estimated even if there is no market for indexed bonds (cf. expressions (3.9) and (3.10), and (4.2) and (4.3)), counter to what is the case in the first way above.

It is well known that the standard consumption asset pricing model cannot explain the US equity premium, the average excess return on stocks over bonds. Therefore various other asset pricing models have been tried. Using another asset pricing model just boils down to making different specifications about the marginal rate of substitution, $\mathscr{K}\left(t, t^{\prime}\right)$ (as long as the representative investor assumption is maintained). Cochrane and Hansen (1992) and Weil (1992) have recently discussed different such specifications. These specifications can be readily incorporated in the present framework. ${ }^{20}$

20 The relative consumption model, a specification along the lines of Abel (1990), is discussed extensively in Weil (1992). It is especially easy to handle since it just replaces the log of the marginal rate of substitution (in the discrete time case) with

$$
m\left(t, t^{\prime}\right)=-\gamma\left[\ln \left(C_{t^{\prime}}-\alpha C_{t^{\prime}-1}\right)-\ln \left(C_{t}-\alpha C_{t-1}\right)\right]-\rho\left(t^{\prime}-t\right)
$$




\section{Conclusions}

A unified treatment of term, inflation and foreign exchange risk premia has been provided, as a step in evaluating the usefulness of forward interest rates as indicators of market expectations of future interest rates, inflation rates and currency depreciation rates. The relevant premia have been defined as the appropriate expected excess return: on a forward contract for the term premium, on a nominal bond over a real bond for the inflation risk premium, and on a domestic bond over a foreign bond for the foreign exchange risk premium. For the present purpose the relevant term premium is the forward term premium, rather than the holding period or rollover term premium.

Under an asset pricing assumption, and an assumption of conditional lognormality of the relevant variables, explicit and intuitive expressions for the risk premia have been derived. The risk premia each consist of two terms, a variance term and a covariance term. The variance term arises from Jensen's inequality, since asset prices are convex functions of interest rates and inflation rates. The variance term enters with a negative sign for the term and inflation risk premia, with a positive sign for the foreign exchange risk premium. The covariance term is the negative of the covariance between the appropriate excess return and the marginal rate of substitution. In a consumption asset pricing model the covariance term simplifies to the covariance between excess return and consumption. In the capital asset pricing model, the covariance term simplifies to the covariance between the excess return and the market portfolio.

The risk premia can be estimated in two different ways. The first way is direct regression of realized excess returns on variables in the information set. This has the advantage of not relying on a particular asset pricing model, but the drawback that data on real interest rates on real bonds are required for the real term premium and for the inflation risk premium.

where $C_{t}$ is consumption and $a>0$ is a constant measuring the relative consumption effect. 
The second way is to use a specific asset pricing model and the corresponding specific expressions for the risk premia. This has the advantage of not requiring data on real bond rates, but the drawback of using a more restrictive maintained hypothesis.

If estimation results in premia of negligible size, forward interest rates can be used directly as indicators of expected future interest rates, inflation rates and currency depreciation rates. If estimation results in nonnegligible premia, constant or time-varying, this does not imply that forward interest rates are useless as indicators, only that they need to be corrected by estimates of the premia. Neither does nonnegligible premia imply an advantage for traditional yield curves over forward rate curves. Regardless of the risk premia, the forward interest rate curve and the yield curve contain the same information, precisely as the marginal cost curve and the average cost curve contain the same information. The forward rate curve only presents that information in a more informative and easily interpreted way. 21

Appendix

1. For $x$ normal

$$
E[\exp (x)]=\exp \left\{\mathrm{E}[x]+\frac{1}{2} \operatorname{Var}[x]\right\}
$$

It follows that for $x$ and $y$ jointly lognormal

$$
\begin{aligned}
& \mathrm{E}[x]=\exp \{\mathrm{E}[\ln x]+\{\operatorname{Var}[\ln x]\} \text { and } \\
& \mathrm{E}[x y]=\mathrm{E}[x] \mathrm{E}[y] \exp \{\operatorname{Cov}[\ln x, \ln y]\}
\end{aligned}
$$

2. Expressions for nominal and real interest rates (the term structure of interest rates): From (2.1) and (A2) it follows that

$$
\begin{gathered}
i(l, T)=-\mathrm{E}_{l}[m(l, T)] /(T-l)-\frac{1}{2} \operatorname{Var}_{l}[m(l, T)] /(T-l) \text { and } \\
r(l, T)=-\mathrm{E}_{l}[m(l, T)] /(T-l)-\frac{1}{2} \operatorname{Var}_{l}[m(l, T)] /(T-l) .
\end{gathered}
$$

3. Derivation of the nominal term premium, $\varphi\left(l, l^{\prime}, T\right)$ :

21 Svensson (1993) further discusses the use of forward interest rates as indicators of monetary policy. 


$$
\begin{gathered}
Q(t, T) \equiv \exp [-i(t, T)(T-t)]=\mathrm{E}_{t}[\mathcal{K}(t, T) P(t) / P(T)]= \\
=\mathrm{E}_{t}\left\{\left[\mathcal{K}\left(t, t^{\prime}\right) P(t) / P\left(t^{\prime}\right)\right]\left[\mathscr{K}\left(t^{\prime}, T\right) P\left(t^{\prime}\right) / P(T)\right]\right\}= \\
=/ \mathscr{K}\left(t, t^{\prime}\right) P(t) / P\left(t^{\prime}\right) \text { and } \mathscr{K}\left(t^{\prime}, T\right) P\left(t^{\prime}\right) / P(T) \text { jointly lognormal } /= \\
=\mathrm{E}_{t}\left[\mathscr{K}\left(t, t^{\prime}\right) P(t) / P\left(t^{\prime}\right)\right] \mathrm{E}_{t}\left[\mathscr{K}\left(t^{\prime}, T\right) P\left(t^{\prime}\right) / P(T)\right] \\
\cdot \exp \left\{\operatorname{Cov}_{t}\left[\dot{m}\left(t, t^{\prime}\right), \bar{m}\left(t^{\prime}, T\right)\right]\right\}= \\
=/ \mathrm{E}_{t}\left[\mathcal{K}\left(t^{\prime}, T\right) P\left(t^{\prime}\right) / P(T)\right]=\mathrm{E}_{t}\left\{\mathrm{E}_{t^{\prime}}\left[\mathscr{K}\left(t^{\prime}, T\right) P\left(t^{\prime}\right) / P(T)\right]\right\} /= \\
=\exp \left[-i\left(t, t^{\prime}\right)\left(t^{\prime}-t\right)\right] \mathrm{E}_{t}\left\{\exp \left[-i\left(t^{\prime}, T\right)\left(T-t^{\prime}\right)\right]\right\} \\
\cdot \exp \left\{\operatorname{Cov}_{l}\left[\dot{m}\left(t, t^{\prime}\right), \bar{m}\left(t^{\prime}, T\right)\right]\right\} .
\end{gathered}
$$

It follows that

$$
\begin{gathered}
\exp \left[-f\left(t, t^{\prime}, T\right)\left(T-t^{\prime}\right)\right]=\mathrm{E}_{t}\left\{\exp \left[-i\left(t^{\prime}, T\right)\left(T-t^{\prime}\right)\right]\right\} \\
\cdot \exp \left\{\operatorname{Cov}_{l}\left[\dot{m}\left(t, t^{\prime}\right), \bar{m}\left(l^{\prime}, T\right)\right]\right\}= \\
=/ i\left(t^{\prime}, T\right) \text { normal } /= \\
=\exp \left\{-\mathrm{E}_{l}\left[i\left(t^{\prime}, T\right)\right]\left(T-l^{\prime}\right)+\frac{t}{t} \operatorname{Var}_{l}\left[i\left(t^{\prime}, T\right)\right]\left(T-t^{\prime}\right)^{2}\right\} \\
\cdot \exp \left\{\operatorname{Cov}_{t}\left[\dot{m}\left(l, l^{\prime}\right), \dot{m}\left(l^{\prime}, T\right)\right]\right\} .
\end{gathered}
$$

Hence,

$$
\begin{gathered}
\varphi\left(t, t^{\prime}, T\right) \equiv f\left(t, t^{\prime}, T\right)-\mathrm{E}_{l}\left[\left(l^{\prime}, T\right)\right] \equiv \\
\equiv-\frac{1}{2} \operatorname{Var}_{l}\left[i\left(t^{\prime}, T\right)\right]\left(T-t^{\prime}\right)-\operatorname{Cov}_{l}\left[\bar{m}\left(l, l^{\prime}\right), \bar{m}\left(l^{\prime}, T\right)\right] /\left(T-t^{\prime}\right) .
\end{gathered}
$$

4. For instantaneous-(maturity) term premia, exploit that for $t<t^{\prime}<T$,

$$
\lim _{T \rightarrow t^{\prime}} \operatorname{Cov}_{t}\left[x\left(t^{\prime}\right), x(T)-x\left(t^{\prime}\right)\right] /\left(T-t^{\prime}\right)=\operatorname{Cov}_{t}\left\{x\left(t^{\prime}\right), \lim _{T \rightarrow l^{\prime}} \mathrm{E}_{t^{\prime}}\left[x(T)-x\left(t^{\prime}\right)\right] /\left(T-t^{\prime}\right)\right\}
$$

To see this, note that

$$
\begin{gathered}
\operatorname{Cov}_{l}\left[x\left(t^{\prime}\right), x(T)-x\left(t^{\prime}\right)\right] /\left(T-t^{\prime}\right)=\operatorname{Cov}_{t}\left\{x\left(t^{\prime}\right), \mathrm{E}_{t^{\prime}}\left[x(T)-x\left(t^{\prime}\right)\right]+x(T)-\mathrm{E}_{t^{\prime}} x(T)\right\} /\left(T-t^{\prime}\right)= \\
=\operatorname{Cov}_{t^{\prime}}\left\{x\left(t^{\prime}\right), \mathrm{E}_{t^{\prime}}\left[x(T)-x\left(t^{\prime}\right)\right]\right\} /\left(T-t^{\prime}\right)=\operatorname{Cov}_{l^{\prime}}\left\{x\left(t^{\prime}\right), \mathrm{E}_{l^{\prime}}\left[x(T)-x\left(t^{\prime}\right)\right] /\left(T-t^{\prime}\right)\right\},
\end{gathered}
$$

since $\operatorname{Cov}_{t}\left[x\left(l^{\prime}\right), x(T)-E_{t} x(T)\right] \equiv 0$.

5. Derivation of the spot inflation risk premium, $O\left(l^{\prime}, l^{\prime}, T\right)$ :

$$
\begin{aligned}
Q\left(t^{\prime}, T\right) / \tau\left(t^{\prime}, T\right)= & \left.e^{-\left[i\left(l^{\prime}, T\right)-r\left(l^{\prime}, T\right)\right]\left(T-l^{\prime}\right)}=\mathrm{E}_{p^{l}} \mid \mathcal{K}\left(l^{\prime}, T\right) P\left(l^{\prime}\right) / P(T)\right] / \mathrm{E}_{i^{\prime}} \mathscr{K}\left(t^{\prime}, T\right)= \\
& =/ \mathcal{K}\left(l^{\prime}, T\right), P\left(l^{\prime}\right) / P(T) \text { jointly lognormal } /= \\
& =\mathrm{E}_{i^{\prime}}\left[P\left(l^{\prime}\right) / P(T)\right] \exp \left\{\operatorname{Cov}_{l^{\prime}}\left[m\left(l^{\prime}, T\right), p\left(l^{\prime}\right)-p(T)\right]\right\}=
\end{aligned}
$$


$=\exp \left\{-\mathrm{E}_{t^{\prime}}\left\{p(T)-p\left(t^{\prime}\right)\right]+\frac{1}{2} \operatorname{Var}_{t^{\prime}}\left[p(T)-p\left(t^{\prime}\right)\right]-\operatorname{Cov}_{t^{\prime}}\left[m\left(t^{\prime}, T\right), p(T)-p\left(t^{\prime}\right)\right]\right\}$

Hence,

$$
\begin{gathered}
\theta\left(t^{\prime}, t^{\prime}, T\right) \equiv i\left(t^{\prime}, T\right)-r\left(t^{\prime}, T\right)-\mathrm{E}_{t^{\prime}} \pi\left(t^{\prime}, T\right)= \\
=-\frac{t}{2} \operatorname{Var}_{t^{\prime}}\left[\pi\left(t^{\prime}, T\right)\right]\left(T-t^{\prime}\right)+\operatorname{Cov}_{t^{\prime}}\left[m\left(t^{\prime}, T\right), \pi\left(t^{\prime}, T\right)\right] .
\end{gathered}
$$

6. The forward inflation risk premium $\theta\left(t, t^{\prime}, T\right)$ is defined for $t<t^{\prime}<T$ as

$$
\theta\left(t, t^{\prime}, T\right) \equiv \mathrm{E}_{t} \alpha\left(t^{\prime}, t^{\prime}, T\right) \equiv \mathrm{E}_{t} i\left(t^{\prime}, T\right)-\mathrm{E}_{t} r\left(t^{\prime}, T\right)-\mathrm{E}_{t} \pi\left(t^{\prime}, T\right),
$$

and it hence fulfills

$$
\theta\left(t, t^{\prime}, T\right)=-\frac{1}{2} \mathrm{E}_{t} \operatorname{Var}_{t^{\prime \prime}}\left[\pi\left(t^{\prime}, T\right)\right]\left(T-t^{\prime}\right)+\mathrm{E}_{t} \operatorname{Cov}_{t^{\prime}}\left[m\left(t^{\prime}, T\right), \pi\left(t^{\prime}, T\right)\right]
$$

In general the operators $\mathrm{E}_{t} \mathrm{Var}_{t}$, and $\mathrm{E}_{t} \mathrm{Cov}_{t}$, cannot be simplified further, since

$$
\mathrm{E}_{t}\left\{\operatorname{Var}_{t^{\prime}}[x]\right\}=\mathrm{E}_{t}\left\{\mathrm{E}_{t^{\prime}}\left[x^{2}\right]+\left[\mathrm{E}_{t}, x\right]^{2}\right\}=\mathrm{E}_{t}\left[x^{2}\right]+\mathrm{E}_{t}\left\{\left[\mathrm{E}_{t}, x\right]^{2}\right\} \text {. }
$$

The second term on the right hand side is in general not equal to $\left[\mathrm{E}_{t} x\right]^{2}$. However, if $\mathrm{E}_{t^{\prime}} x$ conditional upon information available at time $l<t^{\prime}$ is not stochastic but a deterministic function of $t^{\prime}$ and information available at time $\ell$, we have $\mathrm{E}_{t}\left\{\left[\mathrm{E}_{t}, x\right]^{2}\right\}=\left[\mathrm{E}_{t} x\right]^{2}$. Then it follows that $\mathrm{E}_{t}\left\{\operatorname{Var}_{t^{\prime}}[x]\right\}=\operatorname{Var}_{i}[x]$. The variance at $t^{\prime}$ indeed becomes a deterministic function of information available at time $t$. The same argument applies to $E_{t} \operatorname{Cov}_{t}$. To sum up, only if the spot inflation premium at $t^{\prime}, O\left(t^{\prime}, t^{\prime}, T\right)$, is a deterministic function of information available at time / can we in general simplify the expression for the forward inflation premium to be

$$
O\left(t, t^{\prime}, T\right)=-\frac{1}{2} \operatorname{Var}\left[\pi\left(t^{\prime}, T\right)\right]\left(T-l^{\prime}\right)+\operatorname{Cov}_{t}\left[m\left(t^{\prime}, T\right), \pi\left(t^{\prime}, T\right)\right] .
$$

(For specific distributions, we may of course be able to simplify $E_{t} \mathrm{Var}_{{ }^{\prime}}$ even if $\mathrm{Var}_{{ }^{\prime}}$ is stochastic given information available at time $t$.)

7. Derivation of the spot nominal foreign exchange risk premium, $\xi\left(l^{\prime}, l^{\prime}, T\right)$ :

$$
\begin{aligned}
& \exp \left[-i^{*}\left(t^{\prime}, T\right)\left(T-t^{\prime}\right)\right]=\mathrm{E}_{t^{\prime}}\left\{\left[\mathcal{K}\left(l^{\prime}, T\right) P\left(l^{\prime}\right) / P(T)\right]\left[S(T) / S\left(l^{\prime}\right)\right]\right\}= \\
& =\mathrm{E}_{t}\left\{\mathscr{K}\left(l^{\prime}, T\right) P\left(l^{\prime}\right) / P(T)\right\} \mathrm{E}_{t^{\prime}}\left\{S(T) / S\left(l^{\prime}\right)\right\} \\
& \cdot \exp \left\{\operatorname{Cov}_{l^{\prime}}\left[\dot{m}\left(t^{\prime}, T\right), s(T)-s\left(l^{\prime}\right)\right]\right\}= \\
& =\exp \left\{-i\left(l^{\prime}, T\right)\left(T-t^{\prime}\right)\right\} \exp \left\{\mathrm{E}_{t^{\prime}}\left[s(T)-s\left(t^{\prime}\right)\right]+\frac{1}{2} \operatorname{Var}_{t^{\prime}}\left[s(T)-S\left(t^{\prime}\right)\right]\right\} \\
& \cdot \exp \left\{\operatorname{Cov}\left[\dot{l}\left(t^{\prime}, T\right), s(T)-s\left(l^{\prime}\right)\right]\right\} \text {. }
\end{aligned}
$$


Hence,

$$
\begin{aligned}
& \xi\left(l^{\prime}, l^{\prime}, T\right) \equiv i\left(l^{\prime}, T\right)-i^{*}\left(l^{\prime}, T\right)-\mathrm{E}_{t^{\prime}} \delta\left(l^{\prime}, T\right)= \\
= & \frac{1}{2} \operatorname{Var}_{t^{\prime}}\left[\delta\left(l^{\prime}, T\right)\right]\left(T-l^{\prime}\right)+\operatorname{Cov}_{t^{\prime}}\left[\dot{m}\left(t^{\prime}, T\right), \pi\left(l^{\prime}, T\right)\right] .
\end{aligned}
$$

8. The forward foreign exchange risk premium, $\xi\left(l, l^{\prime}, T\right)$, is, for $t<l^{\prime}<T$,

$$
\begin{gathered}
\xi\left(t, t^{\prime}, T\right) \equiv \mathrm{E}_{t} \xi\left(t^{\prime}, l^{\prime}, T\right) \equiv \mathrm{E}_{t} i\left(t^{\prime}, T\right)-\mathrm{E}_{t^{*}} i^{*}\left(t^{\prime}, T\right)-\mathrm{E}_{t} \delta\left(t^{\prime}, T\right)= \\
=\frac{1}{2} \mathrm{E}_{t} \operatorname{Var}_{t^{\prime}}\left[\delta\left(t^{\prime}, T\right)\right]\left(T-t^{\prime}\right)+\mathrm{E}_{t} \operatorname{Cov}_{t^{\prime}}\left[\dot{[m}\left(l^{\prime}, T\right), \delta\left(l^{\prime}, T\right)\right] .
\end{gathered}
$$

If the spot foreign exchange risk premium at time $l$ is a deterministic function of information available at time $t$, the forward exchange risk premium can be simplified to

$$
\xi\left(t, t^{\prime}, T\right)=\frac{1}{2} \operatorname{Var}_{l}\left[\delta\left(t^{\prime}, T\right)\right]\left(T-l^{\prime}\right)+\operatorname{Cov}_{l}\left[\dot{m}\left(t^{\prime}, T\right), \delta\left(t^{\prime}, T\right)\right]
$$




\section{References}

Abel, Andrew B. (1990), "Asset Prices Under Habit Formation and Catching up with the Joneses," American Economic Revicw 80, 38-42.

Adler, Michael, and Bernard Dumas (1983), "International Portfolio Choice and Corporation Finance: A Synthesis," Journal of Finance 38, 925-984.

Bank of England (1993), Inflation Report, August 1993.

Benninga, Simon, and Aris Protopapadakis (1983), "Real and Nominal Interest Rates under Uncertainty: The Fisher Theorem and the Term Structure," Journal of Political Economy 91, 856-867.

Ben-Shahar, H., and Cukierman, Alex (1973), "The Term-Structure of Interest Rates and Expectations of Price Increase and Devaluation," The Journal of Finance 28, $567-575$.

Breeden, Douglas T. (1986), "Consumption, Production, Inflation and Interest Rates: A Synthesis," Journal of Financial Eronomics 16, 3-39.

Cochrane, John, H., and Hansen, Lars Peter (1992), "Asset Pricing Explorations for Macroeconomics," NBER Macroeconomics Annual 1992 7, 115-165.

Cox, John C., Jonathan E. Ingersoll, Jr., and Stephen A. Ross (1981), "A Re-examination of Traditional Hypotheses about the Term Structure of Interest Rates," The Journal of Finance 34, 769-799.

Engel, Charles (1992), "On the Foreign Exchange Risk Premium in a General Equilibrium Model," Journal of Intcrnational Economics 32, 305-319.

Fama, Eugene F., and Farber, André (1979), "Money, Bonds, and Foreign Exchange," American Economic Rcuicw 69, 639-649.

Fischer, Stanley (1975), "The Demand for Indexed Bonds," Joumal of Political Economy $83,509-534$.

Harvey, Campbell R. (1989), "Time-Varying Conditional Covariances in Tests of Asset Pricing Models," Journal of Financial Economics 24, 289-317. 
Hodrick, Robert J. (1987), The Empirical Evidence on the Efficiency of Forward and Futures Foreign Exchange Markets, Jacques Lesourne, and Hugo Sonnenschein, eds., Harwood Academic Publishers, New York.

McCallum, Bennett T. (1990), "Targets, Indicators, and Instruments of Monetary Policy," Working Paper WP/90/41, International Monetary Fund.

Park, Jae Won (1989), "Changing Uncertainty and the Time-Varying Risk Premia in the Term Structure of Nominal Interest Rates," Working Paper, Columbia University.

Paunio, J.J., and Antti Suvanto (1977), "Changes in Price Expectations: Some Tests Using Data on Indexed and Non-Indexed Bonds," Economica 44, 37-45.

Roll, Richard, and Solnik, Bruno (1979), "On Some Parity Conditions Encountered Frequently in International Economics," Journal of Macroeconomics 1, 267-283.

Shiller, Robert J. (1990), "The Term Structure of Interest Rates" (with an Appendix by J. Huston McCulloch), in Benjamin M. Friedman and Frank H. Hahn, eds., Handbook of Monetary Economics, Volume I, North-Holland, Amsterdam, Ch. 13, 627-722.

Stulz, René M. (1981), "A Model of International Asset Pricing," Journal of Financial Economics 9, 383-406.

Stulz, René, M. (1984), "Currency Preferences, Purchasing Power Risks, and the Determination of Exchange Rates in an Optimizing Model," Journal of Money, Credit and Banking 16, 302-316.

Svensson, Lars E.O. (1992), "The Foreign Exchange Risk Premium in a Target Zone with Devaluation Risk," Joumal of Inlcrnational Econonics 33, 21-40.

Svensson, Lars E.O. (1993), "Monetary Policy with Flexible Exchange Rates," in progress.

Weil, Philippe (1992), "Comment on Cochrane and Hansen," NBER Macroeconomics Annual 7, 169-181.

Woodward, Thomas G. (1990), "The Real Thing: A Dynamic Profile of the Term 
Structure of Real Interest Rates and Inflation Expectations in the United Kingdom, 1982-89," Journal of Business 63, 373-398.

Yariv, Daniel (1990), "An Estimate of Inflationary Expectations in Israel Under the Disinflation Programs," Bank of Isracl Economic Review 64, 51-70. 
Figure 1

Nominal and Real Spot and Forward Rates

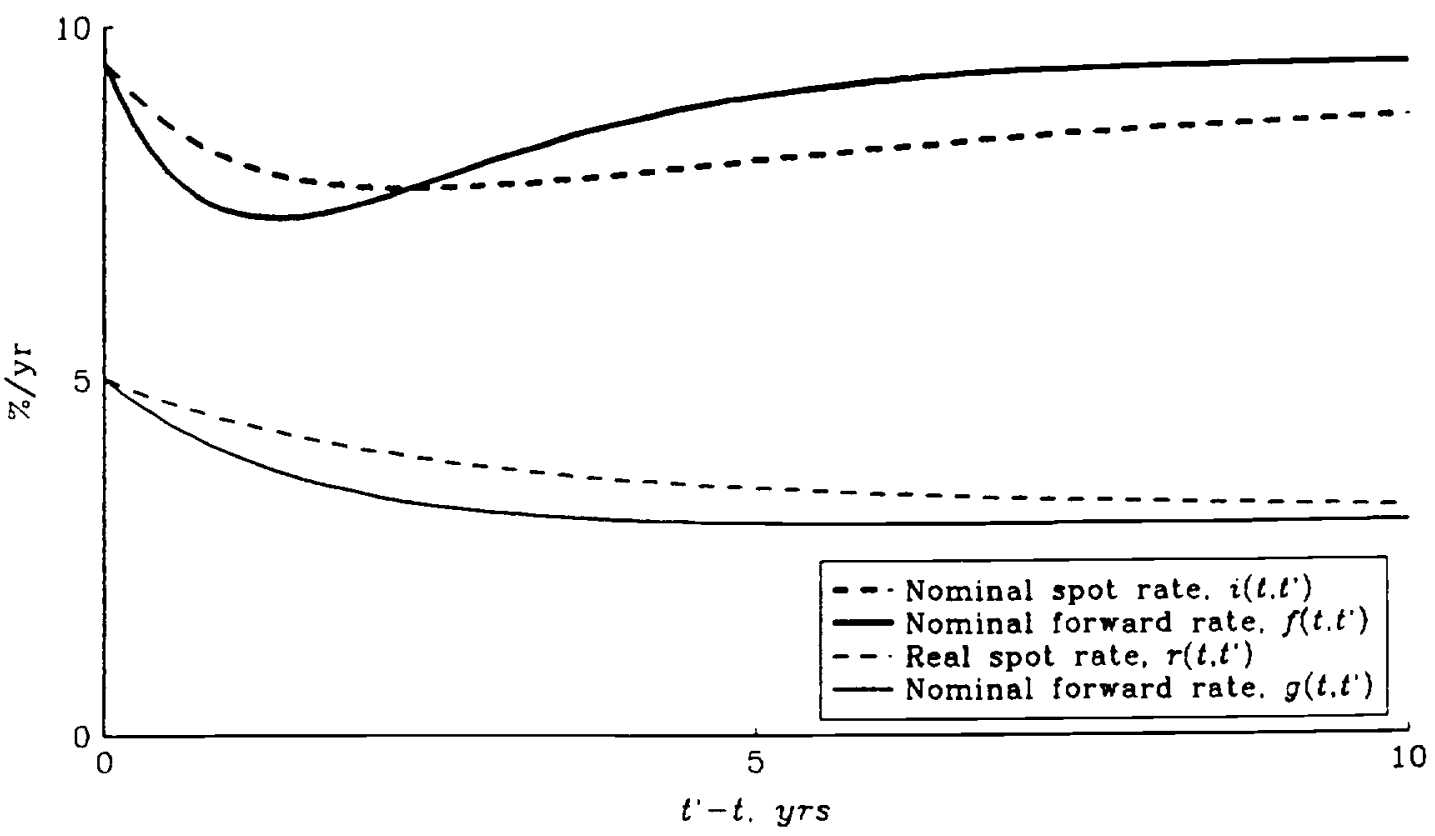

Figure 2

Domestic and Foreign Spot and Forward Rates

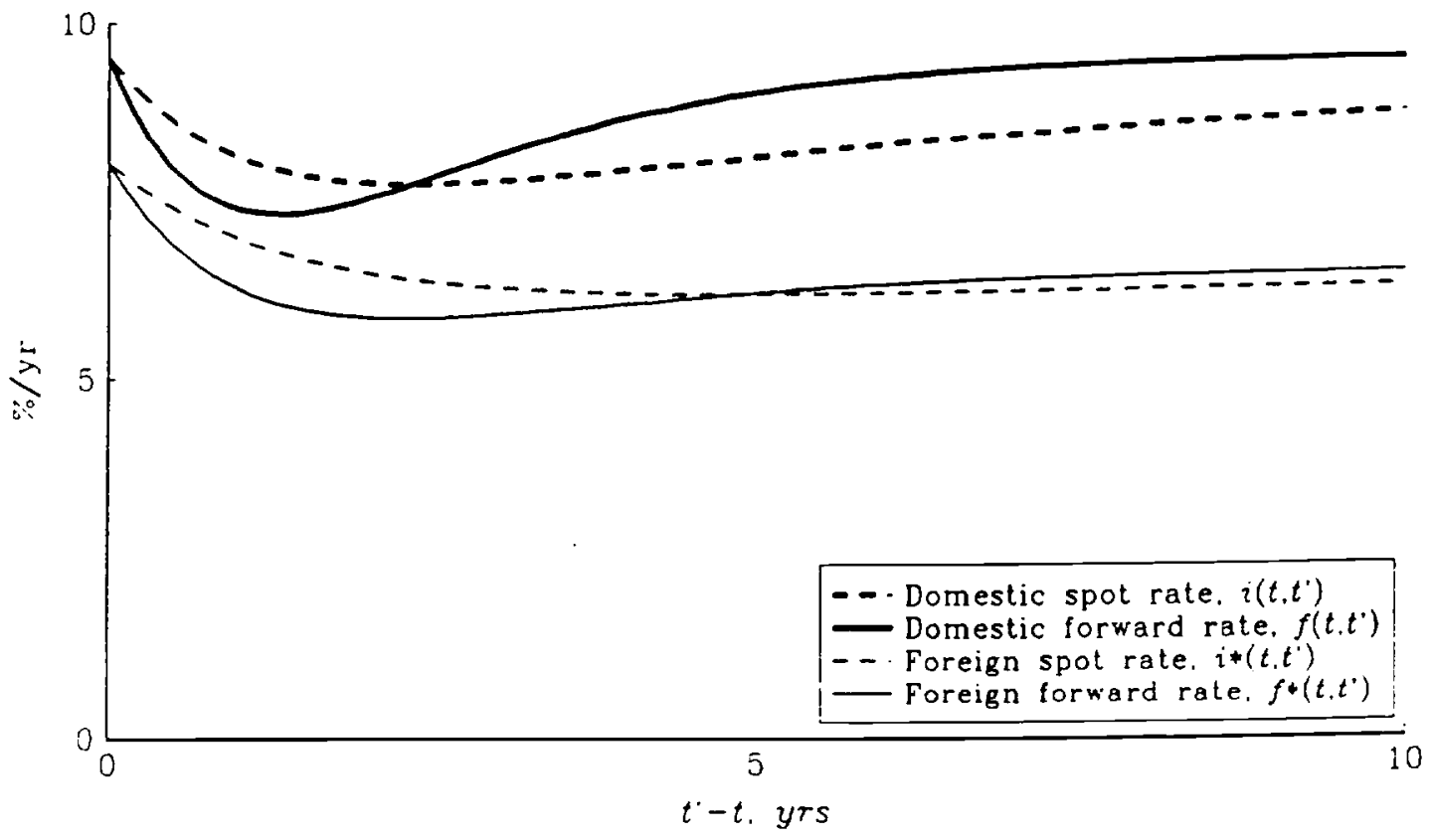

